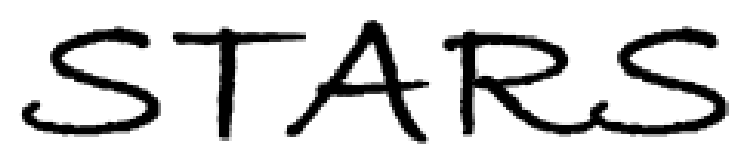

University of Central Florida

STARS

8-1-2009

\title{
An Analysis of the Motivators and Inhibitors Affecting Association Meeting Attendance for Generation X and Baby Boomers
}

Jill Fjelstul

University of Central Florida, jill.fjelstul@ucf.edu

Kimberly Severt

Deborah Breiter

University of Central Florida, Deborah.Breiter@ucf.edu

Part of the Hospitality Administration and Management Commons, and the Tourism and Travel Commons

Find similar works at: https://stars.library.ucf.edu/rosenscholar

University of Central Florida Libraries http://library.ucf.edu

This Paper is brought to you for free and open access by the Rosen College of Hospitality Management at STARS. It has been accepted for inclusion in Rosen Faculty Scholarship and Creative Works by an authorized administrator of STARS. For more information, please contact STARS@ucf.edu.

\section{Original Citation}

Fjestul, J., Severt, K., Breiter, D. (2009). An analysis of the motivators and inhibitors affecting association meeting attendance for Generation X and Baby Boomers. Event Management, 13(1), 31-42.

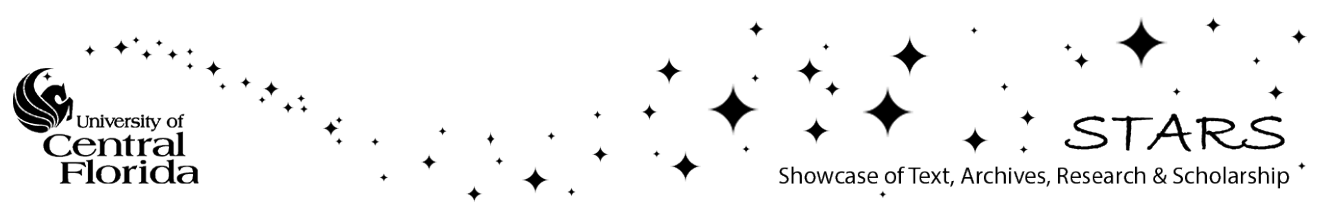




\title{
AN ANALYSIS OF THE MOTIVATORS AND INHIBITORS AFFECTING ASSOCIATION MEETING ATTENDANCE FOR GENERATION X AND BABY BOOMERS
}

\author{
JILL FJELSTUL, KIMBERLY SEVERT, and DEBORAH BREITER \\ Rosen College of Hospitality Management, University of Central Florida, Orlando, FL, USA
}

\begin{abstract}
The objective of the study was to compare the similarities and differences between the inhibitors and motivators of Generation X and Baby Boomers in regard to conference attendance. Specifically, conference attendance motivators and inhibitors were explored and reported. The results will be useful to association managers and conference planners as they design programs for their members to best meet their professional needs.
\end{abstract}

Key words: Associations; Baby Boomers; Conference attendance; Generations; Generation X

\section{Introduction}

The present day's workforce is extraordinary given the diverse backgrounds, experiences, and attitudes of the four generations employed. Large portions of the workforce are members of professional associations. The primary objectives of association planners are to meet their member's educational needs, provide networking opportunities, and support the advancement of the industry as a whole. The Professional Convention Management Association (PCMA), for example, provides association executives, planners, and suppliers with such support. To provide maximum benefit to association members, it is essential that planners understand what may keep their members from attending association meetings (inhibitors) and what motivates their members to attend meetings (moti- vators). Attendance projections and actual conference attendance is a critical financial component of association operations. Approximately 33\% of an association's annual budget is generated from convention attendance (Fenich, 2008). The aim of this study, therefore, was to gain a better understanding of the similarities and differences between the Baby Boomer members and Generation $\mathrm{X}$ members so that association planners may better serve their attendees. The following article provides an overview of the four-generation workforce to offer a better understanding of their behaviors, patterns, and concerns. The article continues with the purpose of the research, the methodology, the findings, and the implications of the present study.

Generations are identifiable by birth year and are potentially influenced by significant life experiences during their personal and professional de- 
velopment. The following provides brief overviews of the four-generation workforce; Matures, Baby Boomers, Generation X, and Generation Y. Matures are also known as the Veterans, Silents, or the Greatest Generation, were born prior to 1945. Matures value family and patriotism, had a parent at home to raise the children, preferred consistency, and generally remained with one company over time (Allen, 2004).

Baby Boomers, born 1945-1964, believe in growth, change, and expansion. Baby Boomers have grown up in an era ranging from unprecedented economic growth to corporate downsizing. Boomers want it all, are willing to work long hours to achieve their goals, and measure success materially (Eisner, 2005; Kupperschmidt, 2000). Boomers tend to be social and attribute networking as key in career-building success. An increased divorce rate for this generation, unfortunately, has been a consequence of their work. Baby Boomers have incurred lifetime employment, seek personal growth opportunities, and have realized personal sacrifice for the benefit of their organization (Bell \& Narz, 2007).

Generation X, born 1965-1980, have been raised by the workaholic Baby Boomer generation just described. Generation X were often referred to as latchkey kids. Parents were often not home during child-rearing years, possibly due to parents working, divorce, or having parents who simply needed multiple jobs to survive financially. Consequently, Generation $\mathrm{X}$ tend to lack social skills but are strong with technology. They tend to be reluctant to network for job advancement. They may be individualistic, be distrustful of corporations, and lack loyalty (Eisner, 2005). In addition, Generation $\mathrm{X}$ view job security as their ability to transfer job skills to future employment opportunities, a reversal shown from the corporate loyalty attribute of the Baby Boomers (Bell \& Narz, 2007). They are unwilling to sacrifice their personal lives for a career (Krug, 1998).

Generation Y, born after 1980, are also known as the Millennials or the Internet Generation. Generation $\mathrm{Y}$ is showing tendencies similar to the Matures-patriotic, sociable, valuing home and family. This generation is the most technically literate, desires intellectual challenge, seeks professional development, and strives to make a difference.
Succeeding personally and professionally, in addition to working collaboratively with co-workers representing their shared values, Generation Y appear to be motivators (Eisner, 2005). Generation Y thrives on new challenges and expects to be given responsibility early in their careers (Glass, 2007). In addition, Generation $\mathrm{Y}$ has a low tolerance for boredom and is very selective in the preference for receiving information (Goman, 2006).

Previous research relating to association and conference participation issues has been evident in the literature. Research has shown that association membership increases retention within the profession (Blau \& Lunz, 1999). Unfortunately, the number of workers seeking professional development opportunities within associations has been found to decline for members older than 55 years of age (Schambach, 2001). Generation X, unsurprisingly, prefers to solve problems by themselves and uncollaboratively (Yrle, Harman, \& Payne, 2005). In regard to compatibility, $60 \%$ of human resource professionals in large companies report conflict between the younger and older workforce (Eisner, 2005). Such generational differences may potentially influence decisions regarding future professional development participation, subsequently affecting conference attendance. There has been little research linking generational behaviors and perceptions with conference attendance. The present study was designed to fill this research gap.

\section{Purpose of the Study}

The purpose of this study was to identify the motivators and inhibitors to conference attendance by Baby Boomers and Generation X to determine if similarities and difference exist. Although data were collected from all four generational groups (Generation Y, Generation X, Baby Boomers, and Matures), the focus of this study was on the comparison between Generation X's and Baby Boomers' motivators and inhibitors to attend meetings and conventions. As evident in this study, these two generational groups attribute to the majority of association membership and annual meeting attendance. Generation Y are often starting in entrylevel positions and may not have the money to join or attend a professional conference if their employers are not supplementing the cost. The 
Matures are soon to leave the profession and may not feel a conference will benefit them enough to justify the expense.

\section{Methodology}

A survey was developed to identify the motivators for and inhibitors to meeting attendance. These items were derived from a thorough literature review and by using industry experts' knowledge from information collected by their members in the past. There were 22 motivators and 16 inhibitors. Additional questions regarding demographics were added. The survey was evaluated by the PCMA Industry Research Committee for clarity and time needed to complete it. Their suggestions were incorporated into the final survey prior to distribution. The online survey included 16 questions, ranging from general demographics to motivating and inhibiting factors of meeting attendance. Several of the questions had many variables, so the actual number of items was greater than 16 .

PCMA leaders identified four association meeting planners, all of whom were PCMA members, to participate in the study. These planners emailed their association members, alerting them to the fact that they would be receiving a link to an anonymous survey regarding meeting attendance. The four planners sent a second e-mail that included a letter from the researchers explaining the research project, the informed consent process, and the survey link. Each participating association planner was then asked to send out a third e-mail to their association members, approximately one week after the second e-mail, thanking them for participation in the survey and/or to remind them to fill out the survey.

The survey used a convenience sampling technique based on voluntary participation of PCMA Board and Committee Members and Association Planners. Each survey link had a special code to identify the specific association data. For purposes of this study, data were analyzed collectively; however, the researchers coded each association's data to provide feedback to each association. Doing this provided an incentive for associations to participate. Data were received electronically and stored on a password-protected computer. Survey results were entered into SPSS for data analysis.
Descriptive statistics were calculated for many of the survey questions. To identify the similarities and differences between the two generational groups, a comparison of means were analyzed, and then factor analysis was used to collapse the motivating variables into a limited number of factors to gain a better understanding of how the motivations group together and allowed the similarities and differences to be determined. This process was followed for the motivators of Generation X, the motivators of Baby Boomers, the inhibitors of Generation X, and inhibitors of Baby Boomers. By following this process, the researchers were able to make a comparison between the two generational groups.

\section{Results}

\section{The Respondents}

A total of 5,591 surveys were distributed. The first association had 480 members and a response rate of $5 \%$. The second association had 1,137 members and a response rate of $11 \%$. The third association had 1,953 members and a response rate of $17 \%$. The fourth association had 2,021 members and a response rate of $19 \%$. More specific to the present study, there were a total of 788 respondents from the two generation groups (Generation $\mathrm{X}$ and Baby Boomers). There were a total of $164(20.8 \%)$ Generation X respondents and 624 (79.2\%) Baby Boomer respondents. From the Generation X respondents, 35 (21.3\%) were male and $129(78.7 \%)$ were female. From the Baby Boomer respondents, 109 (17.5\%) were male and $511(81.9 \%)$ were female. A summary of the demographics is provided in Table 1 .

\section{Reliability of Scale}

Cronbach alphas range from 0 to 1.0 and indicate the extent to which the items in an index are measuring the same thing (Vogt, 1993). The threshold for an acceptable Cronbach alpha is $>0.70$. For this study, the motivators resulted in a Cronbach alpha of 0.89 and inhibitors resulted in a Cronbach alpha of 0.86 . The items were derived from an extensive literature review and industry consultation. 
Table 1

Demographics

\begin{tabular}{lcc}
\hline & Frequency & Percentage \\
\hline Generational Groups & & \\
Generation X & 164 & $20.8 \%$ \\
Baby Boomers & 624 & $79.2 \%$ \\
$\quad$ Total & 788 & $100 \%$ \\
Generation X & & \\
Male & 35 & $21.3 \%$ \\
Female & 129 & $78.7 \%$ \\
$\quad$ Total & 164 & $100 \%$ \\
Baby Boomers & & \\
Male & 109 & $17.5 \%$ \\
Female & 511 & $81.9 \%$ \\
Missing data & 4 & $0.6 \%$ \\
$\quad$ Total & 624 & $100 \%$ \\
\hline
\end{tabular}

\section{Mean Comparison}

The first analyzes was a comparison of means for the items of the motivators and inhibitors for both generations. Tables 2 and 3 provide a summary of the means, standard deviations, and numbers of respondents for the given items.

\section{Principal Component Analysis}

Principal component analysis was used to explore the dimensions of the motivators and inhibitors used in this study for the two generational groups analyzed. In principal component analysis, the "components" reflect the common and unique variance of the variables that are the motivators and inhibitors explored in the study. To determine if the data set was suitable for factor analysis, two issues were considered: (1) the ratio between the number of variables and sample size, and (2) the intercorrelations among items. The ratio between sample size and motivators for Generation $\mathrm{X}$ was $164: 22$, and the ratio between sample size and motivators for Baby Boomers was 624:22. The ratio between sample size and inhibitors for Generation $\mathrm{X}$ was $164: 16$, and ratio between sample size and inhibitors for Baby Boomers was 624:16. These ratios are quite adequate according to $\mathrm{Di}$ lorio (2005), who stated that Nunnally (1978) recommended a 10:1 ratio even though others recommend a 15:1 ratio. The ratio between the number of Generation $\mathrm{X}$ respondents and the number of

Table 2

Means of Motivators for Generation X and Baby Boomers

\begin{tabular}{|c|c|c|c|c|c|c|c|}
\hline Motivators for Generation X & Mean & $S D$ & $N$ & Motivators for Baby Boomers & Mean & $S D$ & $N$ \\
\hline Educational purposes & 1.56 & 1.13 & 162 & Educational purposes & 1.62 & 1.22 & 618 \\
\hline Relevance of conference topic & 1.66 & 1.18 & 162 & Relevance of conference topic & 1.67 & 1.20 & 617 \\
\hline Career enhancement & 1.88 & 1.07 & 162 & Continuing education credits & 2.09 & 1.46 & 616 \\
\hline Hearing new research in my field & 2.04 & 1.09 & 161 & Hearing new research in my field & 2.10 & 1.16 & 613 \\
\hline Financial support from employer & 2.10 & 1.26 & 162 & Travel cost & 2.13 & 1.23 & 615 \\
\hline Continuing education credits & 2.17 & 1.43 & 161 & Financial support from employer & 2.14 & 1.33 & 615 \\
\hline Business networking opportunities & 2.18 & 1.13 & 162 & Cost of accommodations & 2.15 & 1.23 & 617 \\
\hline Travel cost & 2.19 & 1.20 & 162 & Accessible location & 2.16 & 1.14 & 614 \\
\hline No holiday conflicts & 2.20 & 1.22 & 161 & Cost of registration & 2.20 & 1.21 & 616 \\
\hline Cost of accommodations & 2.20 & 1.17 & 162 & Time availability & 2.24 & 1.19 & 614 \\
\hline Cost of registration & 2.22 & 1.15 & 162 & No holiday conflicts & 2.30 & 1.33 & \\
\hline Time availability & 2.27 & 1.14 & 160 & Career enhancement & 2.30 & 1.22 & 616 \\
\hline Accessible location & 2.31 & 1.17 & 162 & Length of conference & 2.33 & 1.12 & 613 \\
\hline No conflicts with other conferences & 2.41 & 1.21 & 160 & Business networking opportunities & 2.37 & 1.27 & 615 \\
\hline Spending time with like-minded people & 2.43 & 1.06 & 161 & Spending time with like-minded people & 2.38 & 1.14 & 612 \\
\hline Attractive location & 2.48 & 1.15 & 161 & No conflicts with other conferences & 2.51 & 1.27 & 615 \\
\hline Length of conference & 2.49 & 1.09 & 161 & Attractive location & 2.55 & 1.13 & 615 \\
\hline Being actively involved in the association & 2.50 & 1.17 & 161 & Being actively involved in the association & 2.70 & 1.12 & 614 \\
\hline Participation in the meeting & 2.58 & 1.18 & 161 & Participation in the meeting & 2.76 & 1.09 & \\
\hline Learning from different generations & 2.65 & 1.18 & 160 & Learning from different generations & 2.76 & 1.19 & \\
\hline Time away from the office & 2.91 & 1.13 & 159 & Time away from the office & 2.82 & 1.22 & 609 \\
\hline Meeting friends & 3.08 & 1.24 & 161 & Meeting friends & 3.11 & 1.23 & \\
\hline Making new friends & 3.20 & 1.22 & 161 & Making new friends & 3.17 & 1.19 & 614 \\
\hline
\end{tabular}

Scale: $1=$ to a great extent to $5=$ to no extent. 
Table 3

Means of Inhibitors for Generation X and Baby Boomers

\begin{tabular}{|c|c|c|c|c|c|c|c|}
\hline Inhibitors for Generation $\mathrm{X}$ & Mean & $S D$ & $N$ & Inhibitors for Baby Boomers & Mean & $S D$ & \\
\hline Total costs for attendance too high & 2.06 & 1.17 & 161 & Topics not of interest to me & 2.05 & 1.24 & \\
\hline Family obligations & 2.20 & 1.25 & 161 & Total costs for attendance too high & 2.15 & 1.27 & \\
\hline Time conflict with work/family & 2.22 & 1.12 & 161 & Accommodation costs too high & 2.20 & 1.24 & \\
\hline $\begin{array}{l}\text { Lack of financial support from em- } \\
\text { ployer }\end{array}$ & 2.25 & 1.38 & 162 & Lack of financial support from employer & 2.23 & 1.41 & 618 \\
\hline Topics not of interest to me & 2.29 & 1.28 & 161 & Workload at my job & 2.52 & 1.14 & 617 \\
\hline Accommodation costs too high & 2.32 & 1.24 & 161 & Accommodations are unsatisfactory & 2.58 & 1.24 & \\
\hline Workload at my job & 2.40 & 1.15 & 161 & Time conflict with work/family & 2.58 & 1.24 & 615 \\
\hline $\begin{array}{l}\text { Financial hardship if I attend the } \\
\text { meeting }\end{array}$ & 2.72 & 1.46 & 161 & Family obligations & 2.70 & 1.32 & \\
\hline Accommodations are unsatisfactory & 2.76 & 1.29 & 160 & Financial hardship if I attend the meeting & 2.72 & 1.44 & \\
\hline Delivery mode of meetings & 2.80 & 1.14 & 161 & eeting too long & 2.79 & 1.11 & \\
\hline $\begin{array}{l}\text { Length of meeting is too short to jus- } \\
\text { tify trip }\end{array}$ & 2.81 & 1.29 & 161 & $\begin{array}{l}\text { Length of meeting is too short to justify } \\
\text { trip }\end{array}$ & 2.79 & 1.23 & \\
\hline Length of meeting too long & 2.90 & 1.14 & 161 & Delivery mode of meetings & 2.82 & 1.09 & \\
\hline $\begin{array}{l}\text { Location of meeting was too far from } \\
\text { home }\end{array}$ & 2.98 & 1.42 & 161 & $\begin{array}{l}\text { Location of meeting was too far from } \\
\text { home }\end{array}$ & 2.97 & 1.34 & \\
\hline $\begin{array}{l}\text { Location of meeting was not desir- } \\
\text { able }\end{array}$ & 3.00 & 1.35 & 161 & Location of meeting was not desirable & 3.00 & 1.28 & \\
\hline Family unable to travel with me & 3.16 & 1.51 & 161 & $\begin{array}{l}\text { Meeting location's surrounding area was } \\
\text { not of interest to myself/my family }\end{array}$ & 3.55 & 1.26 & \\
\hline $\begin{array}{l}\text { Meeting location's surrounding area } \\
\text { was not of interest to myself/my } \\
\text { family }\end{array}$ & 3.43 & 1.39 & 161 & Family unable to travel with me & 3.74 & 1.31 & 610 \\
\hline
\end{tabular}

Scale: $1=$ to a great extent to $5=$ to no extent.

motivator variables did not quite meet this criterion. However, because the nature of the study is to explore the similarities and differences, the researchers feel the ratio was sufficient enough to meet the objectives of the study and serve as a baseline for future comparisons.

To address the second issue, the correlation matrix was examined to determine if most of the coefficients were greater than 0.3. Two statistical measures further determined whether the data were suitable for this analysis: Kaiser-MeyerOlkin (KMO) determines if the sample was adequate and Bartlett's test of sphericity or the test of correlations among variables. According to Tabachnick and Fidell (2001), 0.6 is suggested as a minimum value for a good factor analysis; the KMO was 0.802 for Generation $\mathrm{X}$ motivators, 0.850 for the Baby Boomer motivators, 0.802 for Generation X inhibitors, and 0.843 for the Baby Boomer inhibitors. The results of the Bartlett's test was significant at $p<0.000$ for all four analysis.

A factor with an eigenvalue greater than 1 was the basis for determining which factors were re- tained. Concurrently, a variable was determined to sufficiently load on a factor if it had a factor loading of 0.50 and higher (Hair, Anderson, Tatham, \& Black, 1998).

\section{Similarities and Differences in Motivations Between Generation X and Baby Boomers}

For Generation X, the motivators collapsed into six factors accounting for $75.7 \%$ of the total variance explained. The first factor, named "Professional Development," included five items: (1) educational purposes, (2) relevance of conference topics, (3) hearing new research in my field, (4) career enhancement, and (5) financial support from employer. The first factor accounted for $29.9 \%$ of variance. The second factor, named "Reasonable Cost," included three items: (1) cost of registration, (2) cost of accommodations, and (3) travel costs. The second factor accounted for $14.5 \%$ of variance. The third was named "Socialization" and included four items: (1) meeting friends, (2) making new friends, (3) spending time 
with like-minded people, and (4) learning from different generations. The third factor accounted for $10.8 \%$ of the total variance. The fourth factor was named "Schedule" included three items: (1) length of conference, (2) no conflicts with other conferences, and (3) no holiday conflicts. The fourth factor accounted for $8.2 \%$ of the total variance. The fifth factor was named "Involvement" and included two items: (1) participation in the meeting, and (2) being actively involved in the association. The fifth factor accounted for $6.3 \%$ of the total variance. The last factor was named "Personal Benefit" included two items: (1) attractive location, and (2) continuing education credits. This factor accounted for the remaining $6 \%$ of the total variance. Four items were eliminated in the analysis due to insufficient loading or double loading. These items were: time away from the office, accessible location, time availability, and networking opportunities.

The factor analysis results for Baby Boomer motivators collapsed into six factors and accounted for $74.9 \%$ of the total variance explained. The first factor was named "Reasonable Cost" and included four items: (1) cost of registration, (2) cost of accommodations, (3) travel costs, and (4) length of the conference. The first factor accounted for $35 \%$ of variance. The second factor was named "Professional Development" and included six items: (1) hearing new research in my field, (2) relevance of conference topic, (3) educational purpose, (4) spending time with like-minded people, (5) learning from different generations, and (6) business networking opportunity. The second factor accounted to $13.9 \%$ of the total variance. The third factor was named "Socialization" and included two items: (1) meeting friends, and (2) making new friends. The third factor accounted for $7.5 \%$ of the total variance. The fourth factor was named "Personal Benefit" and included three items: (1) attractive location, (2) accessible location, and (3) continuing education credits. The fourth factor accounted for $6.8 \%$ of the total variance. The fifth factor was named "Schedule" and included two items: (1) no conflicts with other conferences, and (2) no holiday conflicts. The fifth factor accounted for $5.9 \%$ of the total variance. The last factor was named "Involvement" and included two items: (1) participation in the meeting, and (2) being actively involved in the association; this factor accounted for $5.7 \%$ of the total variance. Table 4 summarizes the factor analysis results of the motivators for both Generation $\mathrm{X}$ and the Baby Boomers.

\section{Similarities and Differences in Inhibitors Between Generation X and Baby Boomers}

For Generation X, the inhibitors collapsed into four factors accounting for $66 \%$ of the total variance explained. The first factor was named "Cost Issues" and included four items: (1) total cost for attendance too high, (2) accommodation cost too high, (3) lack of financial support from employer, and (4) financial hardship if I attend. The first factor accounted for $33.3 \%$ of variance. The second factor was named "Undesirable Location" and included four items: (1) meeting location surrounding area was not of interest, (2) location of meeting was not desirable, (3) location of meeting too far from home, and (4) accommodations are unsatisfactory. The second factor accounted for $13.2 \%$ of variance. The third factor was named "Undesirable Meeting Programming" and included four items: (1) delivery mode of meeting, (2) topics not of interest to me, (3) length of meeting too short to justify trip, and (4) length of meeting is too long. The third factor accounted for $11.9 \%$ of the variance. The fourth factor was named "Other $\mathrm{Ob}$ ligations" and included four items: (1) time conflict with work or family, (2) family obligations, (3) family unable to travel with me, and (4) workload at my job. The fourth factor accounted for $7.6 \%$ of the total variance.

The factor analysis results for Baby Boomer inhibitors collapsed into four factors and accounted for $61.3 \%$ of the total variance explained. The first factor named "Undesirable Meeting Programming" and included five items: (1) delivery mode of meeting, (2) topics not of interest to me, (3) accommodations are unsatisfactory, (4) length of meeting too short to justify trip, and (5) length of meeting is too long. The first factor accounted for $32.9 \%$ of variance. The second factor was named "Cost Issues" and included four items: (1) total cost for attendance is too high, (2) accommodation cost too high, (3) lack of financial support from employer, and (4) financial hardship if I attend. 
Table 4

Factor Analysis Comparison between Generation X and Baby Boomers: Motivators

\begin{tabular}{|c|c|c|c|}
\hline Generation X & $\begin{array}{l}\text { Factor } \\
\text { Score }\end{array}$ & Baby Boomers & $\begin{array}{l}\text { Factor } \\
\text { Score }\end{array}$ \\
\hline Factor 1: Personal Development (29.9 \%) & & Factor 1: Reasonable Cost $(35 \%)$ & \\
\hline Relevance of conference & 0.863 & Cost of accommodations & 0.928 \\
\hline Educational purposes & 0.849 & Travel cost & 0.926 \\
\hline Career enhancement & 0.747 & Cost of registration & 0.919 \\
\hline Financial support from employer & 0.668 & Length of conference & 0.683 \\
\hline Hearing new research in my field & 0.745 & & \\
\hline Factor 2: Reasonable Cost (14.5\%) & & Factor 2: Professional Development (13.9\%) & \\
\hline Cost of registration & 0.924 & Hearing new research in my field & 0.724 \\
\hline Cost of accommodations & 0.917 & Relevance of conference topic & 0.714 \\
\hline \multirow[t]{4}{*}{ Travel cost } & 0.912 & Educational purpose & 0.710 \\
\hline & & Spending time with like-minded people & 0.704 \\
\hline & & Learning from different generations & 0.580 \\
\hline & & Business networking opportunity & 0.526 \\
\hline Factor 3: Socialization $(10.8 \%)$ & & Factor 3: Socialization $(7.5 \%)$ & \\
\hline Make new friends & 0.822 & Making new friends & 0.889 \\
\hline Learning from different generations & 0.727 & Meeting friends & 0.851 \\
\hline Meeting friends & 0.706 & & \\
\hline Spending time with like-minded people & 0.626 & & \\
\hline Factor 4: Schedule $(8.2 \%)$ & & Factor 4: Personal Benefit $(6.8 \%)$ & \\
\hline No conflicts with other conferences & 0.843 & Attractiveness of location & 0.857 \\
\hline No holiday conflicts & 0.787 & Accessible location & 0.694 \\
\hline Length of conference & 0.701 & Continuing education credits & 0.525 \\
\hline Factor 5: Involvement (6.3\%) & & Factor 5: Schedule (5.9\%) & \\
\hline Being actively involved & 0.883 & No holiday conflicts & 0.843 \\
\hline Participation in meeting & 0.859 & No conflicts with other conferences & 0.838 \\
\hline Factor 6: Personal Benefit (6.0\%) & & Factor 6: Involvement $(5.7 \%)$ & \\
\hline Attractive location & 0.829 & Participation in the meeting & 0.873 \\
\hline Continuing education credits & 0.755 & Being actively involved in the association & 0.856 \\
\hline Total variance explained $(75.7 \%)$ & & Total variance explained $(74.9 \%)$ & \\
\hline
\end{tabular}

The second factor accounted for $11.7 \%$ of the total variance. The third factor was named "Undesirable Location" and included four items: (1) meeting location's surroundings area was not of interest, (2) location of meeting was not desirable, (3) family unable to travel with me, and (4) location of meeting was too far from home. The third factor accounted for $8.7 \%$ of the total variance. The fourth factor was named "Other Obligation" and included three items: (1) family obligations, (2) time conflicts with work or family, and (3) workload at my job. The fourth factor accounted for $8.0 \%$ of the total variance. Table 5 provides a summary of the factor analysis results of the inhibitors of both Generation X and the Baby Boomers.

\section{Discussion}

The purpose of the present study was to determine whether there was a difference in motivators and inhibitors when comparing Generation $\mathrm{X}$ and Baby Boomers in their decisions to attend conferences. Findings from this study suggest that motivators and inhibitors are relatively similar for Generation X and Baby Boomer conference attendees, even though the literature is replete with differences in perceptions and behaviors between the two generations. In fact, the six factors identified as the leading motivators for conference attendance were consistent from a generational perspective, varying only slightly in order of influence for each generation. Likewise, the four factors identified as leading inhibitors to conference attendance by generation were also similar and varied slightly in influence.

Generation X considered professional development opportunities as the leading influence for conference attendance. Such findings are consistent with the literature, supporting the notion that 
Table 5

Factor Analysis Comparison between Generation X and Baby Boomers: Inhibitors

\begin{tabular}{|c|c|c|c|}
\hline Generation X & $\begin{array}{l}\text { Factor } \\
\text { Score }\end{array}$ & Baby Boomers & $\begin{array}{r}\text { Factor } \\
\text { Score }\end{array}$ \\
\hline Factor 1: Cost Issues (33.3\%) & & Factor 1: Undesirable Meeting Programming (32.9\%) & \\
\hline Total cost for attendance too high & 0.870 & Delivery mode of meeting & 0.731 \\
\hline Accommodation cost too high & 0.811 & Topics not of interest to me & 0.728 \\
\hline Lack of financial support from employer & 0.785 & Accommodations are unsatisfactory & 0.661 \\
\hline Financial hardship if I attend & 0.705 & $\begin{array}{l}\text { Length of meeting is too short to justify trip } \\
\text { Length of meeting is too long }\end{array}$ & $\begin{array}{l}0.654 \\
0.624\end{array}$ \\
\hline Factor 2: Undesirable Location (13.2\%) & & Factor 2: Cost Issues $(11.7 \%)$ & \\
\hline Meeting location surrounding area was not of interest & 0.821 & Total cost for attendance is too high & 0.796 \\
\hline Location of meeting was not desirable & 0.804 & Accommodation cost too high & 0.777 \\
\hline Location of meeting was too far from home & 0.654 & Lack of financial support from employer & 0.743 \\
\hline Accommodations are unsatisfactory & 0.518 & Financial hardship if I attend & 0.724 \\
\hline Factor 3: Undesirable Meeting Programming (11.9\%) & & Factor 3: Undesirable Location (8.7\%) & \\
\hline Delivery mode of meeting & 0.859 & Meeting location's surrounding area was not of interest & 0.827 \\
\hline Topics not of interest to me & 0.763 & Location of meeting was not desirable & 0.723 \\
\hline Length of meeting is too short to justify trip & 0.636 & Family unable to travel with me & 0.623 \\
\hline Length of meeting is too long & 0.572 & Location of meeting was too far from home & 0.615 \\
\hline Factor 4: Other Obligations ( $7.6 \%$ ) & & Factor 4: Other Obligations $(8.0 \%)$ & \\
\hline Time conflict with work or family & 0.733 & Family obligations & 0.796 \\
\hline Family obligations & 0.730 & Time conflict with work or family & 0.761 \\
\hline Family unable to travel with me & 0.590 & Workload at my job & 0.498 \\
\hline Workload at my job & 0.571 & & \\
\hline Total variance explained $(66.0 \%)$ & & Total variance explained $(61.3 \%)$ & \\
\hline
\end{tabular}

Generation $\mathrm{X}$ are in need of professional development (O’Bannon, 2001). Generation X, by virtue of their work cycle, would be searching for career enhancement opportunities. A reasonable cost associated with conference attendance was the second leading motivator for Generation $\mathrm{X}$ in their decision to attend conferences. This is not surprising in times of budget reductions and the current state of the economy.

Baby Boomers, however, reversed the order of these influences. Baby Boomers considered a reasonable cost as the most influential factor in determining their conference presence, followed by professional development opportunities. It is our assumption that Baby Boomers have most likely participated in professional development opportunities during their career. Therefore, they have most likely had financial outlay for such attendance. It is not surprising that reasonable cost would be a leading contributor to their decision to attend a conference. Reasonable cost included cost of registration, accommodations, and travel expenses by both generations. Baby Boomers also noted length of conference as a cost-related variable. Socialization was the third motivating factor for conference attendance by both generations. Both generations were similar in their definition of socialization, depicted in Table 2 by score and definition. Generation $\mathrm{X}$ identified meeting of new and present friendships, learning from other generations, and spending time with like-minded people as variables related to the socialization influence. Baby Boomers listed meeting and making new friends. This is an encouraging finding because a goal for planners would be to bring both generations together for educational and social experiences.

The fourth, fifth, and sixth conference attendance motivators varied slightly between Generation $\mathrm{X}$ and the Baby Boomers. Such variation, however, may offer the identifiable uniqueness between the generations. Table 2 outlines each factor and their related scores. Generation $\mathrm{X}$ revealed program agenda as their fourth factor of influence. Such findings would support previous discussion in that Generation $\mathrm{X}$ is in need of professional development for career enhancement. Personal involvement in the meetings and location of the conference were the fourth and fifth motivators, respectively. The surprising finding was the per- 
sonal involvement in meetings interest by Generation $\mathrm{X}$. This appears to contradict literature in that Generation $\mathrm{X}$ is more individualistic and tends not seek advice from others (Eisner, 2005). This finding is encouraging for planners because it would appear that Generation X may be motivated to get involved in future conferences.

Personal benefit was revealed as the biggest difference in motivators between generations. Personal benefit was the sixth factor for Generation $\mathrm{X}$, whereas Baby Boomers viewed personal benefit as their fourth factor of influence. Attractiveness of location was an item related to personal benefit. Baby Boomers most likely have attended conferences in the past. Overtime, conference locations may be repeated. Such duplication may or may not influence attendance by Baby Boomers. Generation X, on the other hand, may not have the longevity in conference attendance, subsequently not experiencing duplication of venues. Scheduling, the fourth motivating factor for Generation X and the fifth for Baby Boomers, offered similar items of influence with one exception, length of conference. Involvement was the fifth motivating factor for Generation $\mathrm{X}$ and the sixth for the Baby Boomers. Items were similar for both generations.

Findings from the present study revealed four inhibiting factors influencing the decision to not attend a conference. The inhibitors for Generation $\mathrm{X}$ were costs too high, location of the conference, an undesirable meeting agenda, and other obligations. Inhibitors for the Baby Boomers were undesirable meeting agenda, costs too high, an undesirable location, and other obligations. The greatest difference found between Generation X and Baby Boomers was an undesirable meeting agenda. Baby Boomers noted an undesirable meeting agenda as the leading influence to not attend a conference, whereas Generation $\mathrm{X}$ ranked an undesirable meeting agenda as its third inhibitor. Most likely, Baby Boomers have attended conferences in their past, and thus are more critical in their analysis of the meeting agenda content. Cost issues, as previously noted, were identified as the leading inhibitor for Generation $\mathrm{X}$ and the second inhibitor for the Baby Boomers. A closer look into cost issues of attending conferences raises the discussion of evaluating all costs of attendance collectively versus a potential attendee's subjective analysis of each item of influence separately. There are multiple items of influence to consider: total cost, accommodation cost, financial support (or lack thereof) from their respective employer, and the financial hardship an attendee may endure as a result of their attendance.

\section{Conclusions}

There are limitations associated with the present study. One consists of the sample of respondents. Due to participation from only four associations, it would be difficult to conclude that the present findings can be generalized to all associations. According to Fenich (2008), there are over 177,000 associations in the United States. The data were reported as group data across the four different associations and did not take into consideration the type of association; however, some similarities and differences appeared among the generational groups. Nevertheless, the present study may serve as a catalyst for future action plans for association planners and future research opportunities.

Association planners are continually committed to serving the needs of their members. The aim of this study was to gain a better understanding of the similarities and differences between Baby Boomers and Generation Xers so that association planners may better serve their attendees. Motivators and inhibitors to conference attendance were identified. Surprisingly, the findings identified little difference between the generations. This lack of difference, however, may prove beneficial to planners when planning future meetings.

It would be our recommendation to focus on professional development, cost, socialization, and conference location issues. Planners should note that professional development was a key influence to attending meetings. Although challenging, planners should search for cost-effective deliveries and agenda schedules for future professional development opportunities. A reasonable cost for attendance was also depicted as a major influence for attendance. Suggestions to adhere to the cost factor may include reducing the number of days required for attendance at the meetings and/or offering partial programming via distance education modalities. Third, socialization was reported as a 
leading influence for attendance. It would be our recommendation to offer interactive professional development and socialization opportunities attractive to all generations. One suggestion is for the creation and/or expansion of a mentorship program, not only for the attendees but also for the association. Such consideration would connect all generations in professional development activities and on a social level. Additionally, encouraging a mentorship program where the Baby Boomers, and quite possibly the Matures, become mentors to Generations $\mathrm{X}$ and $\mathrm{Y}$ would enhance involvement within the association, provide a unique professional development experience for all, and increase socialization opportunities for members and attendees. Such a link might also temper the lack of trust and individualism often associated with Generation X, as previously documented. Generation $\mathrm{X}$ tend to be free agents and have received very little training, organized development, and/or mentoring in the workplace. Generation $\mathrm{X}$ will soon be the population to replace the retiring Baby Boomers and efforts to increase their involvement and collaborative efforts should be implemented. Last, location of the meeting was a noted influence for conference attendance. Professional development and socialization can take place anywhere. Location, therefore, may be the deciding influence for attendance. Overall cost of attendance will be directly linked to location. Both attractiveness and cost should be considered when deciding on a future venue.

\section{Future Research}

Future research opportunities are plentiful. The present study focused on Generation X and Baby Boomers, but there are two additional generations in the workforce-Generation Y and the Matures. Generation $\mathrm{Y}$ is just entering the workforce and may or may not be active participants in their related associations. The Matures may or may not be active in associations but would possibly be great resources and advocates for their respective association and membership. Thus, future research should target Generation Y without losing sight on Generation X, Baby Boomers, and the Matures. We recommended that focus groups be held with undergraduate and graduate students, because Generation $\mathrm{Y}$ is the main target population for fu- ture association membership, to identify motivators and inhibitors to their future meeting attendance. PCMA alone has 622 student members, and a significant number of them attend the annual convention. This would present an excellent opportunity for PCMA members to gain insight into career and professional development intentions of the youngest generation in the workforce. Another possible study could investigate the issue of loyalty because this appears to be a common concern for Generation Y. Literature remains unclear as to whether the generation will be loyal to a leader, an organization, or a profession. Social networking is extremely popular with Generation $\mathrm{Y}$ and the younger members of Generation $\mathrm{X}$, expressing themselves via the networking sites of Facebook, MySpace, and MyYearbook. We recommend that associations explore affiliations with social networking sites as an alternative vehicle for promoting membership and meeting activities and for connecting all generations in conference-related activities. Finally, continual research is recommended to identify if factors are generational in nature, thus changing as the members age, or if generation-specific factors identified will remain somewhat unchanged as one group transitions into their next generation category.

\section{References}

Allen, P. (2004). Welcoming Y. Benefits Canada, 28(9), 51-53.

Bell, N. S., \& Narz, M. (2007). Meeting the challenges of age diversity in the workplace. CPA Journal, 77(2), 56-59.

Blau, G., \& Lunz, M. (1999). Testing the incremental effect of professional commitment on intent to leave one's profession beyond the effects of external, personal, and work-related variables. Journal of Vocational Behavior, 52, 260-269.

Di lorio, C. (2005). Measurement in health behavior: Methods in research and evaluation. San Francisco: JosseyBass.

Eisner, S. P. (2005). Managing generation Y. S.A.M. Management Journal, 70(4), 4-15.

Fenich, G. (2008). Meetings, expositions, events and conventions (2nd edition). Englewood Cliffs, NJ: Pearson Prentice Hall.

Glass, A. (2007). Understanding generational differences for competitive success. Industrial and Commercial Training, 38(2), 98-103.

Goman, C. K. (2006). Communicating for a new age. Strategic Communication Management, 10(5), 8-9. 
Hair, J., Anderson, R., Tatham, R., \& Black, W. (1998). Multivariate data analysis (5th edition). Singapore; Pearson Education.

Krug, J. (1998). Understanding generation X. Journal of Management in Engineering, 14(6), 18-19.

Kupperschmidt, B. (2000). Multi-generation employees: Strategies for effective management. Health Care Manager, 19(1), 65-76.

Nunnally, J. C. (1978). Psychometric theory. New York: McGraw-Hill.

O'Bannon, G. (2001). Managing our future: The generation $\mathrm{X}$ factor. Public Personnel Management, 30(1), 95-109.
Schambach, T. (2001). Age, motivation and participation in professional development. Journal of Computer Information Systems, 41(4), 58-65.

Tabachnick, B. G., \& Fidell, L. S. (2001). Using multivariate statistics (4th ed.). Boston: Allyn and Bacon.

Vogt, P. W. (1993). Dictionary of statistics and methodology: A nontechnical guide for the social sciences. Newbury Park, CA: Sage Publications.

Yrle, A., Harman, S., \& Payne, D. M. (2005). Generation $\mathrm{X}$ : Acceptance of others and teamwork implications. Team Performance Management, 11(5/6), 188-199. 